\title{
Dualidade e Unidade de Jurisdição no Brasil
}

\author{
Conferência pronunciada, em francês, no "Institut de Droit Comparé de \\ I'Université de Paris". (*) .
}

J. Guilherme de Aragão

\section{I - DUALIDADE DE JURISDIÇÃO NO IMPÉRIO}

$\mathrm{E}_{\mathrm{M}}$ matéria de Justiça administrativa o Império do Brasil adotou o sistema de dualidade de jurisdição baseado na separação entre as autoridades administrativas e judiciárias. Tal sistema suscita o problema do contencioso administrativo que, no caso brasileiro, encontra suas raizes em dois terrenos diversos - o direito colonial, de origem portuguêsa, e o direito público francês.

Se, por um lado, o direito colonial contribuiu para êsse contencioso com elementos estáticos e conservadores, o direito público francês, por seu lado, deu-1he sólida contribuição doutrinária. Tal foi a influência dêste último, que o Conselho de Estado buscou nele as doutrinas e opiniões dos autcres franceses de Direito Administrativo, da época, e dos Conselheiros de Estado da França. Os publicistas e os Conselheiros de Estado do Império prestaram ao Direito público francês entusiásticas homenagens, reconhecendo-lhe a autoridade.

E' o que se verifica ao folhear as coletâneas de avisos reunidos por HrNRIQUE DO REgo BARROS em seus "Apontamentos sôbre o Contencioso Administrativo" (Rio - 1874).

E' ċe admirar que nossos publicistas e estadistas não tenham aproveitado o desenvolvimento do contencioso francês, para melhorarem o nosso. Assim é que, até o alvorecer da República, o Conselho de Estado brasileiro funcionou como uma espécie de Conselho de Estado do período napoleônico.

O regulamento de 1942 kaseava-se, em muitos casos, na legislação francesa da Revolução e do Diretório. Contudo, bem pouco se modificou até 1889 . Durante cêrca de meio século, nosso contencioso administrativo pendeu para os processos de conflitos e nunca transpôs a etapa obsoleta da Justiça homologável (1) e do ministro-juiz. Foram os revolucionários de 1889 que puseram de lado êsse anacronismo, que se erguia como um fantasma em meio aos poderes do Estado.

(*) Tradução de MARIA DE LOURdes Lima Modiano.

(1) Regime de justiça em que a decisão da autoridade administrativa depende, para se tornar definitiva, da homologação do Chefe do Estado. 
O curioso é que o contencioso administrativo que, na França, aparecera em conseqüência da separação dos Poderes, foi suprimido no Brasil em nome dessa mesma separação. Foi dêsse paradoxo que nasceu a unidade de jurisdição no Brasil.

Mas a obra revolucionária dos republicanos de 1889 inverteu a ordem imperial estabelecida. Ao govêrno parlamentar sucedeu o govêrno presidencial; ao império unitário, a República federativa; à instituição de uma Justiç. comum, a dualidade de Justiça, que reservou lugar especial para os processos até então afetos ao contencioso administrativo, então extinto.

A exemplo do duplo direito anglo-americano o novo Estado relegou à Justiça local das várias unidades da Federação as questóes de Direito privado e de Direito penal, reservando na Justiça Federal, chamada especial, urn iugar para os processos relativos a divergências entre o Estado e o particular. Assim, passou o contrôle judiciário a incidir sôbre os atos administrativos, dando início à nossa segunda experiência jurisdicional.

\section{II - O CONSELHO DE ESTADO DO IMPÉRIO}

A experiência da dualidade de jurisdição processou-se através do Conselho de Estado do Império. Havia, porém, igualmente, abaixo do Conselho de Estado, jurisdições de natureza mais tipicamente contenciosa, com competência para decidir litígios com autoridade de coisa julgada e utilizando normas processuais mais precisas do que as da jurisdição superior. Era o cảso do Tribunal do Tesouro e das tesourarias provinciais. Observa-se, igualmente, que o contencioso administrativo apresentava traços mais acentuados e mais definidos no tocante às matérias dependentes do contencioso colonial, isto é, questóes referentes ao fisco e à administração financeira do Tesouro.

Em outras palavras, o Tribunal do Tesouro e as Tesourarias provinciais tinhan competência para decidir definitivamente, ao passo que nunca ficou esclareciclo se o Conselho de Estado teria simplesmente atribuições consultivas ou se estas seriam jurisdicionais. O Tribunal do Tesouro e as Tesourarias resolviam, além disso, verdadeiros litígios entre a Administração e particulares.

Mas o Conselho de Estado, no Brasil, tal como o Conselho de Estado francês, surgiu como órgão consultivo, junto à autoridade governamental máxima e a direção suprema dos negócios públicos. Para o Brasil, tornou-se, assim, instrumento mcderador do $4 .^{\circ}$ Poder exercido pelo Imperador, entre os trés poderes clássicos do Estado.

Em resumo, nosso Conselho de Estado foi apenas um poder moderador, funcionando junto ao Imperador e, nessa qualidade, foi, sobretudo, um órgão consultivo. Suas atribuições jurisdicionais se revelavam por dedução e, ao exercê-las, o Conselho de Estado transtormara-se em órgão central do conten. ciosn administrativo com competencia para resolver os conflitos suscitados pelas autoridades administrativas ou judiciárias e para julgar, em grau de recurso, as questões examinadas pelas jurisdições e autoridades jurisdicionais inferiores.

Com a Lei n..$^{\circ} 234$, de 23-11-1841, completada pelo Regulamento n. ${ }^{\sigma} 124$, de $5-2-1942$, as atribuições consultivas do Conselho de Estado ficaram bem definidas. Seu âmbito de ação estendeu-se desde as graves e complexas qứes- 
tões que interessavam o exercício do Poder Moderador, até a atividade regulamentar, relativa à administração central e à administração provincial. Sob êsse aspecto, cabia-1he ainda preparar projetos de lei e elabotrar regulamentos administrativos, quer em consequêencia de consultas do Imperador, quer de iniciativa própria. Nesta rubrica podemos reunir tôdas as atribuições que o Visconde de Uruguai cometeu ao exercício do Poder Moderador, do Poder Executivo, Político ou Governamental e do Poder Administrativo Gracioso. Convém acentuar a atividade regulamentar. $\mathrm{O}$. Império baseava-se numa organizaçâo administrativa de tipo unitário. As províncias brasileiras eram sujeitas às mesmas leis, aos mesmos regulamentos gerais que o govêrno central. As leis locais, elaboradas nas Assembléias Provinciais devem ser coerentes com as leis gerais. Daí, novas atribuições conferidas ao Conselho: exame das leis provinciais, inclusive quanto à redação de novas leis, regulamentos, instruções e decretos, de aplicação locaí.

As funções contenciosas atribuídas ao Conselho de Estado pelos texios acima referidos surgiram com a idéia de evitar intromissões de autoridade. Intromissões por parte da autoridade judiciária na autoridade administrativa, muitn mais do que desta naquela. O princípio era o seguinte: quando o Presidente de uma Província ou o Procurador da Corôa junto ao Govêrno Imperial e da província do Rio de Janeiro tiveram conhecimento de que a autoridade judiciária está julgando um processo administrativo, deverão exigir que a mesma lhe preste informações precisas e, ainda, que declare as razões pelas quais conheceram do processo. Se o Presidente ou o Procurador consideraram ter havido intromissão, ordenarão à autoridade judiciária que interrompa o curso d) processo, dando às partes um prazo razoável para apresentarem defesa. Expirado êsse prazo, se as referidas autoridades considerarem que o caso é da esfera adrıinistrativa, darão uma decisão provisória, que comunicarão ao Ministro da Justiça. Por outro lado, se considerarem a questão da alçada do Judiciário, resclverão o conflito, encaminhando o mesmo ao juiz comum, que será, então, competente.

$E^{\prime}$ evidente que êsse dispositivo dá certa prioridade à autoridade administrativa, uma vez que a mesma poderá suscitar o conflito e resolver a questão. 'Tal solução corresponde ao conflito positivo.

Quanto ao conflito negativo, seria mister pedir o pronunciamento do Conselho de Estado, segundo o Regulamento, que estatuía: se a autoridacle administrativa e a autoridade judiciária não se considerarem competentes para a mesma questão, a seção do Conselho de Estado dará parecer, ouvidas ambas aquelas autoridades.

De um modo geral, em caso de conflito positivo, a autoridade administrativa se pronunciava e, à autoridade judicial cabia apenas o recurso ao Conselho de Estado. O conflito sendo negativo, dependeria diretamente do Conselho de Estado.

\section{III - O PROBLEMA DA COMPETÊNCIA ADMINISTRATIVA}

Além da questão de conflitos, o problema da competência administrativa surge ainda em dois tipos de questões: as apreensões marítimas e as dívidas do Estado. Neste último caso, principalmente, o Brasil inspirou-se no contencioso francês. Assim, as dívidas do Estado são resolvidas administra- 
tivamente. Princípios gerais de competência surgirão pelas cpiniões dos publicistas 6 pelas decisões do Conselho de Estado, em relação aos seu fututo funcionamento.

No tocante à separação entre as autoridades administrativas e judiciárias, o contencioso francês parte do princípio de que se deve impedir intromissões recíprocas. Ao Corpo Legislativo e até mesmo ao Rei é vedado exerccr o Poder Judiciário. Em compensação, êste não pode, em hipótese alguma, intervir nas atribuições daqueles.

Tôdas essas distinções encontram sua mais completa expressão no princípio fundamental do contencioso administrativo francês - a separação entre as autoridades administrativas e judiciárias. Segundo a lei de 6-24 de agôsto de 1790 , as funções judiciárias são distintas e permanecem separadas das funções administrativas. Os juízes não podem, sem incorrer nas penas da lei, perturbar, de modo algum, as operaçóes dos corpos administrativos, nem citar, perante êles, os administradores em virtude de suas funções.

A Constituição de 15-16 Frutidor réforçou tal princípio, vedando, taxativamente, aos tribunais conhecerem dos atos de administração de qualquer espécie, para penalidades legais.

O resultado foi a existência de um setor reservado às funções judiciárias e de um outro reservado às funções administrativas. $\mathrm{E}$ da interdição das intromissões de um, poder por outro, o Direito francês chegou à delimitação de duas espécies de autoridade e funções jurisdicionais.

Nosso contencioso administrativo - insistimos - parte da possibilidade de um conflito, que é preciso evitar, entre autoridades adminstrativas e judiciárias. Se o Presidente da Província, o Procurador da Corôa ou ainda, qualquer autoridade administrativa tiver ciência de que o juiz judiciário conhecev de uma matéria da alçada administrativa, que levantem imediatamente o conflito de atribuições - é êste o princípio básico de nosso contencioso, ex presso no artigo 24 do Regulamento $n .^{\circ} 124$, de 5 de fevereiro de 1841 , e reforçado pelo artigo 38 do Decreto n. $^{\circ} 2.548$, de 10 de março de 1860 .

Ainda a propósito dêsse rígido dispositivo legal, o Conselheiro Marquês d: São Vicente - Pimenta Bueno - observou, em sua declaração de voto, no Aviso do Conselho de Estado datado de 22 de deizembro de 1866 , que nada existe fora do Regulamento de 1842 e do Decreto n. $^{\circ} 2.548$, de 1860.

De qualquer forma, é o critério do conflito que, em primeiro plano, permite separar o contencioso administrativo do contencioso judiciário. Depois, é a jurisprudência do Conselho de Estado e a doutrina de nossos publicistas que fixam alguns princípios.

Ncsso Conselho de Estado situou, em várias ocasiões, o lugar de cada ordem jurisdicional. Assim foi que proclamcu, em seu Aviso de 30 de novenibro de $187 \%$, que a independência das autoridades administrativas em face das autoridades judiciárias é, de tal forma, uma realidade, que náo sòmente veda às autoridades de um Poder intervirem em outros Poderes, como, ainda, não permite que qualquer magistrado ou funcionário administrativo seja perturbado pela autoridade judiciária ou por qualquer outra. Citando a autcridade de Vivien, afirma ainda, num outro "Aviso" que as funções judiciárias atribuídas aos juízes e aos tribunais têm por objetivo a execução das leis civis em suas relações com os indivíduos e a propriedade. Nestas con- 
diçōes, a autoridade judiciária toma conhecimento apenas dos casos particulares.

O contrário acontece com relação às autoridades administrativas às quais cabe fazer executar as leis segundo os interêsses gerais e locais, desenvolver e proteger a riqueza pública, representar o Estado como proprietário dos bens nacionais, julgar administrativamente as reclamações e os fatos relativos aos bens públiccs e tomar decisões sôbre contestações, que a execução das leis pode provocar quer entre administradores e administrados, quer entre um particular e uma pessoa jurídica.

Êsses exemplos mostram que a idéia mestra da separação entre as duas rategorias foi posta em equação e que o Conselho de Estado conseguiu estabelecer o princípio da justiça administrativa, que pode ser assim resumida: da separação entre as autoridades administrativas e judiciárias originou-se a instituição da justiça administrativa.

Entre nossos autores, tal princípio deduz-se ainda do espírito da Constituição de 1824 e é calcada também na doutrina francesa.

O Conselheiro Antônio Joaquim Ribas expõe que, segundo a Constituição imperiaí, o Poder Judiciário compõe-se de Juizes e Jurados, que funcionam junto aos tribunais civis e criminais; sua competência limita-se às questões civis e criminais, sem entrar nô terreno administrativo. Qualquer doutrina contrária esclarece Ribas, não se coadunaria com o princípio de independência dos poderes, consagrado no artigo 98 da Constituição, uma vez que o Poder Executivo volveria a uma situação de dependência e subordinação em face do Pcder Judiciário, se seus atos fossem subordinados a confirmação, por parte dêste último, e-se as partes tivessem que outorgar poderes ao mesmo, sob pretexto de terem sido por aquele, lesados em seus direitos.

Enıbora a Constituição imperial não estatua o mesmo princípio de separação, reconhece o Conselhiro Prudêncio Giraldes Tavares da Veiga Cabral que a separação dos poderes judiciário e administrativo é o princípio funde. mirital, no qual se baseia nossa política, desde 25 de março de 1824; desta separação bem definida dos dois poderes (judiciário e administrativo) decorre normalmente a instituição da Justiça administrativa, por isso que administrar é garantir a execução das leis no interêsse geral e local; é tomar precauções úteis aos interêsses da agricultura, do comércio e da indústria. Mas, para garantir a execução das leis, faz-se mister conferir ao Poder Executıvo o direito de afastar os obstáculos e tomar decisões sôbre as reclamações. De outro modo, impossível seria administrar, pois a Administração ficaria scm independência.

Além das razões de ordem constitucional encontramos entre êsses autores razões de utilidade pública, para justificar a existência de uma jurisdição adninistrativa independente do Poder Judiciáro. Essa tendência, porém, é posta ainda mais em evidência por um autcr mais moderno, José Rubino de Oliveira, que publicou em São Paulo, em 1884, seu "Epitome de Direito Administrativo Brasileiro". Segundo êsse autor, por motivo utilitários e práticos, a administração deve ser expedita e enérgica. Assim, nenhum juiz ou tribunal judiciário pode ter ação sôbre ela, por isso que a Administração agindo com autoridade, deve ser livre e independente. Mas a independència, a presteza da administração desapareceriam se, acaso, se chccasse com outro Pcder. Logo, as autoridades competentes para conhecer das reclamações e 
dos recursos administrativos são as que representam o Poder correspondente e não os juízes e os tribunais judiciários que se opõem à presteza, à liberdade e à independência da administração.

Com o Marquês de São Vicente e o Visconde de Uruguai, chega-se, senão à separação constitucional e legal das autoridades administrativas e judiciárias, mas, pelo menos, à sua separação jurisprudencial e doutrinária.

Surge assim o contencioso administrativo em face do contencioso judiciáric. Em particular, chega-se a afirmar a existência do contencioso administrativo como condição de independência dos poderes do Estado. E' D que afirma ainda o Visconde de Uruguai: encontram-se sempre pessoas que se preocupam em propor ao Poder Judiciário a solução das questões contenciosas. Mas tal procedimento acarretaria as seguintes conseqüências:

a) seria o meio de violar o grande princípio da separação dos poderes;

b) provocaria a intervenção do Poder Judiciário na administração;

c) atravancaria a Administração;

d) suprimiria a responsabilidade, confundindo Administração com Poder Judiciário.

Outro testemunho, igualmente importante e oportuno, por isso que dá idéia da oposição à instituição do contencioso administrativo por parte dos homens públicos do Império, é o do Conselheiro Francisco Gầ Acaiaba de Montezuma, em seu célebre discurso, publicado na Revista do Instituto da Ordem dos Advogados do Rio de Janeiro, em 1869, quando indaga: será contenciosa a Administração que se pronuncia sôbre litígios resultantes do conflito entre direitos particulares e o interêsse público? Não constituirá êsse princípio ameaça mortal à indẹpendência do Poder Judiciário? Não provocará sua divisão? Não haverá como achava o sábio Silvestre Pinheiro Ferreira - abuso monstruoso pelo fato de que os juizes ficam sendo ao mesmo tempo partes em causa? Que aconteceria se tais litígios atingissem as obrigações oriundas dos contratos civis? Se a legislação tem que ser una e igual para todo o país, em face dos fundamentos dos princípios da Justiça universal - por que o Poder Judiciário não exercerá suas atribuições constitucionais, aplicando a lei aos fatos das questões e nas divergências levantadas entre os particulares e $o$ interêsse geral ?

Eis o que responde o próprio Conselheiro Montezuma: "Faça o Govêrno corn que se leia mais Lafarrière, Cormenin, Foucart, Macarel, Laffon, Labedat, Magnitot Delamare e, principalmente, o célebre De Gerando, cujo livro "Institutions de Droit Administratif Français" não constitui apenas um Tesouro riquíssimo de bons princípios mas, além disso, pode servir de modêlo para qualquer obra do gênero".

A. Competência administrativa na França - A jurisdição administrativa, mesmo nessa fase de preponderância da autoridade administrativa sôbre a judiciária, tem seus princípios de competọncia. No contencioso francês, a transformação do regime de Justiça homologável em regime de Justiça dele. gada e o desenvolvimento da justiça delegada a partir de 1872 foram seguidas por uma série de regras e doutrinas sôbre a competência administrativa face à competência judiciária.

Os autores franceses acentuam, geralmente, três tendências doutrinárias. A primeira pertence inteiramente à fase da justiça homologável (1790/1830); 
o segundo período corresponde à transição entre o regime de Justiça homologável e o regime de Justiça delegada e à primeira fase dêste último regime jurisdicional (1930/1896); o terceiro é o da consolidação da evolução dia Justiça rielegada (iniciada em 1896).

Durante o primeiro período - dizem os autores - a competência administrativa era definida quanto a cada processo, segundo a natureza do ato em causa; o segundo período é dominado pela teoria dos atos de império e de gestão; finalmente, ao terceiro período, que começa com o critério do serviçว público (serviço público orgânico ou institucional, serviço público material ou funcional), conduzirá a novas regras quanto à competência administrativa.

B. Competência administrativa no Brasil - No tocante ao Conselho de Estado brasileiro, limitaremos nossa análise comparativa aos dois primeiros períodos. Assim, verificamos inicialmente que nosso contencioso se inspirou no critério dos atos em causa.

1. $\left.{ }^{\circ}\right)$ Os Atos em Causa - Neste terreno, o Conselho de Estado teve que determinar, em numerosos casos, a natureza do ato, em matéria de indenizações, contratos e débitos do Estado, Pelos avisos de 13 de dezembro de 1844 e 24 de outubro de 1845, resolveu que cabia à Administração decidir sôbre outras categorias de indenizações e não apenas quanto a apreensões marítimas. Ampliando a competência administrativa, essa orientação jurispiudencial decorre da lei 234 de 23 de novembro de 1841 , que conferiu ao Conselho de Estado competência para declarar o Estado devedor.

Tal princípio resulta dos prejuízos sofridos pelo Estado em conseqüência de numerosas decisões judiciárias, condenando-o a pesadas indenizações - diz o Conselheiro Areas recordando que, durante a discussão da leı número 234 no Senado, pretendera-se deliberadamente subtrair do conhecimento do Poder Judiciário as ações tendentes a declarar o Estado devedor. E, segundo c Conselheiro Visconde de Uruguai, $e m$ conseqüência de muitas decisões judiciárias condenando o Estado, o Tesouro Nacional teve de sofrer tão pesados ônus que a Assembléia Nacional foi forçada a aplicar contra o Poder Judiciário o artigo 31 do Ato Adicional, por fôrça do qual nenhuma dívida do Estado, oriunda dos fatos de guerra, não podia ser paga s๕m a autorização da Assembléia Geral.

Por isso, a liquidação administrativa dos débitos do Estado ultrapassou o terreno das indenizações de guerra e a competência administrativa abrange igualmente as questões suscitadas em matéria de direitos adquiridos, de in. denizações provenientes de contratos, adjudicíções mercados de fornecimentos, de atos administrativos em geral.

Mas, pondo em jôgo a natureza do ato em causa, o Conselho de Estado colc cou certas questões sob a competência judiciária. O exame de cada questão decidirá a competência administrativa, tanto mais que certos dispositivos isolados encaminham ao Tribunal do Tesouro, aos órgãos fiscais ou ac Conselho de Estado o julgamento de novas questões, acrescentando-lhes uma espécie de competência de atribuições.

Resulta daí que a delimitação da competência, administrativa torna-se semprc difícil, com relação à competência judiciária, mas, em todo caso, é ampla, kastante indefinida e elástica. 
2.. ) Os Atos de Império e de Gestão - Da fase subseqüente, assinalada pela teoria dos atos de gestão e de império, nosso contencioso administrativo adota alguns princípios, ao lado de outros tirados, na maioria, de autores franceses da primeira metade do século XIX. A teoria dos atos de gestão e de império apresenta-se como princípio de competência na jurisprudência de nosso Conselho de Estado. Aqui estão dois exemplos: logo que as autoridades públicas descem à situação de contratantes, elas se colocam em igualdade de direitos com a parte contra a qual estão empenhadas. Neste caso, perdem seu poder de modificar os próprios atos em virtude dos privilégios exorbitantes da Ac̀ministração.

3. $\left.{ }^{\circ}\right)$ Outros Princípios - Além disso, ncsso contencioso do Império adijtou outros princípios de competência administrativa aceitos pela doutrina francesa da época.

O Conselheiro Visconde de Jequitinhonha considera que, segundo os publicistas, três exceções existem à competência administrativa: a ordem constitucional, a ordem civil e a ordem penal. Cada um deles deve ficar fora da Jurisdição Administrativa. E' comum ir-se buscar em Adolphe Cheveau e Foucart a doutrina da jurisdição graciosa e contenciosa e, em conseqüência, da de. terminaçâo da competência administrativa baseada na discussão em tôrno de um interêsse especial da Administração, de um lado, e de um direito individual em causa de outro. nistrativa:

De Leferrière, fixam-se dois pontos básicos sôbre a competência admi-

a) existência de ato especial ou de fato particular da Administração;

b) existência de reclamação ligada a algum interêsse de ordem administrativa.

Por outro lado, a jurisdição administrativa, funcionando como juiz dos conflitos, deve estabelecer limites à competência judiciária. Neste terreno, encontram.se as questões civis e as questões comerciais. Um Aviso do Conselho de Estado de 1872, é favorável à competência judiciária quanto aos litígios em que a administração é parte contratante e não um Poder, o que faz lembrar, mais uma vez, a doutrina dos atos de império e de gestão.

À competência judiciária cabem as questões de "habeas-corpus" - foi o que decidiu o Conselho de Estado em 1888, aplicando uma legislação que atribuía tal competência ao Juiz Judiciário. Todavia, em 1875 o Presidente da Província de Pará havia estatuído em contrário. Finalmente, as questões de heranças, mesmo quando os bens se encontravam sob a custódia ou posse do Estadc, devem ir ao juiz comum.

Acabamos de descrever o terreno impreciso, porém amplo, da competência administrátiva, baseada $€ m$ certos princípios doutrinários do contencioso francês e dos autores franceses. A teoria dos atos de poder e de gestão, dominante na época, não teve para nossos autores do Império, muita atração. Situa-se no centro de um ecletismo de princípios em que vamos encontrar desde os publicistas franceses mais antigos, como Rooderer, Henriun de Pensay, até Vivien e iaferrière. Não se veja aí, afinal qualquer tendência para firmar dou- 
trina. O "Arrêt Blanco", que assinalou nova fase para a construção jurídica da competência administrativa, não poderia ter qualquer influência sôbre nosso contencioso.

\section{IV - RECURSOS ADMINISTRATIVOS}

A jurisdição administrativa do Império comportava o exercício de certos recursos de natureza contenciosa. E' fácil sentir a influência do contecioso francês, mas, na prática, predominavam as praxes do direito de origem portuguesa. Por êsse caminho, os recursos administrativos ligam-se de pieferência ao processo civil local, trazendo do contencioso francês, certos princípios, entre os quais convém destacar o do recurso por excesso de autoridade o qual, aliás, nosso contencioso não conseguiu conhecer em seu verdadeiro alcance legal e doutrinário. Tal lacuna se explica pelo fato de que a notável sisten ıatização dos recursos administrativos do contencioso francês, levada a efeito por E. Laferrière, data apenas do ano de 1896.

\section{$\S 10^{\circ}$ Tipos de Recursos}

À hase do direito local, se estabelece a gama dos recursos da jurisdição fiscal, que é - convém frisar - a mais eficiente do contencioso administrativo do Império. De origem portuguesa são os recursos contra as decisões de primeira instância os órgãos fiscais, como, aliás, os recursos de revisão e de embargo de terceiros, figuras processuais igualmente comuns no contencioso fraticês. Finalmente, o processo administrativo em assuntos fiscais liga-se ao processo colonial da lei de 22 de dezembro de 1761 .

Assim, o contencioso do Império comportava, de um lado, recursos ordinários, simples, contra as decisões jurisdicionais de autoridade inferior junto a autoridade superior e, de outro, os recursos especiais, compreendendo recursos de revista, de revisão, de anulação, e os recursos de embargo e de enibargo de terceiros.

\section{$\S 2 .^{\circ} \quad$ Recurso Ordinário}

Através do recurso ordinário, ataca-se a decisão administrativa mediante apelação. O Conselho de Estado estatuiu assim sôbre as decisões tomadas pelos Presidentes de Província e pelos Ministros de Eștado. O Ministro das Finanças e o Tribunal do Tesouro pronunciam julgamentos sôbre as decisões das autoridades fiscais em matéria de impostos e contas. No tocante ao exercício do recurso ordinário, êsses órgãos aparecem como jurisdições de último graı, para apreciar e julgar decisões tomadas, em última análise, por autoridades que funcionam como júl?es administrativos de primeiro grau. E' o n:esmo princípio que, no contencioso francês, na épcca da Justiça homologável, erigiu o Conselho de Estado em juiz de apelação quanto às decisões dos Conselhos de Prefeitura (hoje tribunais Administrativos) e dos Ministros de Estado.

\section{$\S 3 .^{\circ} \quad$ Recursos especiais}

Quanto ao exercício dos recursos especiais, o de revista nenhum interêsse particular oferece, uma vez que é apresentado em matéria de prestações de contas, junto ao próprio tribunal ('Tribunal do Tesouro) que examina o jul- 
gamento atacado. Deve ser aberto nos casos de êrro de cálculo, de omissão cu de desdobramento de contas e de apresentação de novos elementos de prova. Entre os outros, os recursos de revisão e de anulação, permitem paralelos com o contencioso francês. São encaminhados ao Conselho de Estado, que faz as vêzes de juiz de cassação com relação às jurisdições administrativas de atribuição, que emitiram a decisão objeto de recurso.

O Conselho de Estado julga, como juiz de cassação, as decisões do $\mathrm{Mi}$ ristro da Fazenda e do Tribunal do Tesouro, em matéria fiscal e de contas, e, da mesma forma, as decisões dos demais ministros de Estado no tocante à competência de atribuição, isto é, ao chamado contencioso por determinação legal.

O que é preciso acentuar, ainda, é que o recurso de revisão (contra decisões tomadas pelo Tribunal do Tesouro em matéria de contas), bem como o recurso de anulação, podem ser impetrados por incompetência, violaçao da lei, vício de forma e, ainda, excesso de poder. Vê-se, assim, que o "o excesso de poder" aparece como condição de exercício dos dois tipos de recursos aplicáveis a decisões dos órgãos e das autoridades de natureza juriscuicional, não constituindo, como no caso do contencioso francês, um tipo de recurso contra atos irregulares praticados por autoridades administrativas, como tal.

\section{§ 4..$^{\circ}$ Excesso de Poder}

Nosso sistema de ministro-juiz, de administrador-juiz e da Justiça homologável, no qual seria difícil traçar uma linha definida entre atos administrativos e atos jurisdicionais das autoridades administrativas, não chega a estabelecer contrôle jurisdicional da administração. Se, na França, o recurso de excesso de poder evoluiu, passando de uma forma inicial, simplesmente administrativa, de reclamação de incompetência com relação aos corpos administrativos, para tornar-se instrumento de contrôle jurisdicional dos atos administrativos - se, na França, essa evolução já se esboçara antes de 1872 - no Brasil apenas se introduziu o elemento "excesso de poder" como uma das condições para anular uma decisão mais jurisdicional que administrativa, executória. O fato é que, no Brasil, não existindo distinção válida entre os atos administrativos e os atos jurisdicionais e êstes tendo mais fôrça do que aqueles, o Conselho de Estado brasileiro que era o juiz de anulação, tinha que avaliar, no tocante a cada aso, o elemento "excesso de poder", e apreciar se êste último comportava exação ou abuso de autoridade, e deixar à jurisdição graciosa o cuidado de examinar a irregularidade dos atos administrativos. E' preciso acrescentar os recursos de embargo e de embargo de terceiros. Ambos equivalem aos recursos franceses da mesma denominação. Todavia, já se encontravam no contencioso de origem portuguesa, com as mesmas características do contencioso francês. Perante o antigo Conselho Real já se abrira caminho ao exercício daqueles recursos para os postulantes, estabelecendo-se o recurso de embargo de terceiros a favor de outras pessoas que não o querelante, interessadas em litígio já julgado. E' êste o 'sentido do artigo 7, Tít. III, da lei portuguesa de 22-12-1761. Enquanto a oposição era encaminhada ao Conselho de Estado em caso de êrro de julgamento, o embargo de terceiros era admitido perante o juiz privativo do Tesouro nos casos de execução fiscal, envolvendo a posse. 


\section{$\S 5 .^{\circ} \quad$ A falta de um regime de recursos}

Em conclusão, o contencioso do Império abriga alguns tipos de recurso, mas não segue de recursos administrativos. Neste particular, podemos concluir, mais uma vez, com Rego Barros, que a necessidade e a conveniência dos recursos e a organização de dois graus de jurisdição sempre foram reconhecidos no Império, sendo fato unanimente aceito, que, entre nós. não havia sôbre tão relevante assunto princípios determinados, de modo que se pudesse conceder aos administradores garantias e confiança satisfatórias.

Os prazos para a interposição dos recursos ainda não tinham sido também fixados: na maioria dos casos, era preciso recorrer às Ordenanças portuguesas para declarar aceitáveis os recursos, por falta de condições precisas de aceitabilidade na legislação administrativa, como reconheceu o Conselheiro Areas. Tal era a situação do contencioso do Império até seu último momento.

O que acima expressamos retrata os princípios de separação das autoridades administrativas e judiciárias, o regime de Justiça administrativa, os critérios da fixação de competência e o regime de recursos administrativos de nosso contencioso do Império.

Num tal sistema, em que os publicistas mais representativos da época, como Uruguai, Paraná, Jequitinhonha e Nabuco repelem qualquer idéia de conferir a guai não vê como colocar a função jurisdicional fora do Ministro - num tal regime, a finalidade da Justiça delegada autônoma, longe estava de ter sido atingida. As deficiências eram, aliás, explicáveis até certo ponto, pois ncssos publicistas e conselheiros de Estado falavam antes da instituição da Justiça delegada e, ainda, antes do "Arrêt Bougard" (1881) do "Arrêt Cadot". Todavia, não ignoravam os intuitos de reforma do Conselho de Estado francês e do estabelecimento efêmero da Justiça delegada, em 1848.

De um modo geral, o contencioso francês, que inspirou o nosso, me. lhorot. gradativamente, tanto em sua estrutura como em seu funcionamento, ao passo que nosso contencioso manteve sua estreita estrutura inicial.

O mais grave mal do contencioso do Império foi o de não ir além do Regulamento n. ${ }^{\circ} 142$, de 5 de fevereiro de 1842 , observa Tavares Bastos. Todos nossos grandes autores, desde Uruguai até Bilac Pinto e Seabra Fagundes, são acordes neste ponto. Por faita de organização, sucumbiu aos golpes da revolução de 1889. Como tribunal administrativo, no sentido moderno nosso Conselho de Estado jamais existiu - proclamam aqueles autores. "A República o recebeu; a República o baniu entre suas instituições" - diz Seabra Fagundes.

Mas o que é incontestável é que o Conselho de Estado, a despeito dessas ilustradas opiniões, estava à frente de um regime de jurisdição administrativa, de tipo "homologável" que pressupunha o exercício não apenas do regime do ministro-juiz, ccmo também o do administrador-juit?, ambos frutos de uma fase incipiente do contencioso administrativo.

Não sendo suficientemente esclarecida a Justiça administrativa e exercendo o Conselho de Estado, por fôrça de suas atribuições consultivas, função política, oriunda do poder do Imperador (o Poder Moderador) o contencioso administrativo não pôde, evidentemente, resistir aos republicanos de 1889 . 
Por isso mesmo, Rui Barbosa, rejeitando a idéia de um contencioso administrativo com a República, recorda com desprêzo que êle existira sob o regime imperial. Condenando-o, diz o grande mestre que a Constituição republicana (de 2.4 de fevereiro de 1891) eliminou positivamente os elementos do contencicso administrativo, existente sob a monarquia, fechando a porte a qualquer futura tentativa no sentido de sua restauração.

E, sob o signo dessa aversão ao contencioso administrativo, passamos à nossa segunda experiência jurisdicional, da unidade de jurisdição.

(Continua.)

\section{SUMMARY}

The A. discusses, initially, the duality of jurisdiction, judicial and administrative, in the Brazilian Empire (1882-89) within a unitarian state. The Portuguese and the French public law as the twofoid source of such duality; the conservative influence of the former versus the doctrinal contributions of the latter. The Brazilian Federal Republic (1889. ....) with its (1) tederal and (2) state justice according to the American model; the consequent judicial control upun administrative acts.

suits and on those pertaining to financial administration. The State Council in Brazil,

Competence of the Treasury Court and of the provincial Treasury Agencies on fiscal suits and on those psrtaining to financial administration. The State Council in Brazil, under the Empire, primarily the advisory organ of the Crown, but also entrusted with initiative on legislative matters, evolved to become the highest administrative court in the country. Its capacity as such derived from the necessity of avoiding encroachment of authority, particuiarly on the part of the Judiciary upon Administration.

Administrative jurisdiction as the corollary of the necessity of solving conflicts ket. ween the Judiciary and Administration also prevailed on matters of maritime prizes and of state debts. The doctrine of the French administrative jurisdiction as contrasted with Separation between the judicial and the administrative clearly defined in th.e French system, which evolved from the principle of the "justice retenue" (decisions of administrative magistrates or courts not final but requiring the sanction of the head of the state) to that of delegated justice "justice déleguée".

The idea of administrative justice not expressed in the Brazilian Constitution of 1821, although implicitly contained in its spirit. Administrative justice as an imperative in Brazil, prominent jurists of the 19 th century as well as $k_{y}$ members of the State Council.

The fields of judicial and administrative jurisdiction historically considered both in France and Brazil. The principles that have informed the Brazilian doctrine: (1) the specific sement; (3) the constitutional, civil and penal spheres not comprised within the admin's. trative jurisdiction.

Appellate administrative juristiction in Brazil. The French theoretical influence and that of the Portuguese consuetudinary lax. The ordinary appellation against decisions of al inferior court. The special types of appellation against first instance decisions. The absencu

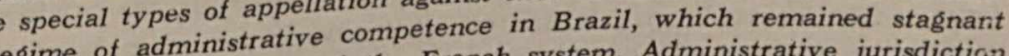
of an ergenized regime of administrative come French system. Administrative jurisdiction

in contrast with the evolutive character of the Reput'ic (1889).
discontinued in Brazil upon the advent of the 